\title{
A multi-year analysis of Canadian Arctic historical weather data in support of solar and wind renewable energy deployment
}

\author{
Adam Wills ${ }^{1 *}$, Carsen Banister ${ }^{1}$, Mathieu Pellissier ${ }^{2}$, and Justin Berquist ${ }^{1}$ \\ ${ }^{1}$ National Research Council Canada, Construction Research Centre, 1200 Montreal Rd., Ottawa, Canada \\ ${ }^{2}$ Concordia University, Building, Civil, and Environmental Engineering, 1455 De Maisonneuve Blvd. W., Montréal, Canada
}

\begin{abstract}
This work explores the importance of renewable resource temporal distribution for solar and wind energy deployment in Arctic communities to meet building and ancillary loads. An analysis of ten years of historic weather data was performed for six locations in the Canadian Arctic to assess renewable resource variation. Simulations of similar capacity solar and wind generation systems were then coupled with the historic data to compare and contrast generation potential. This analysis highlighted the importance of considering hourly, daily, monthly, and year-to-year renewable generation when deploying solar and wind to the Arctic. As many northern communities in Canada have local electricity generation and distribution systems, and no connection to the continental grid, managing grid interactions effectively is crucial to the success of deployment, integration, and operation. The results for the solar energy analysis showed high consistency of production year-to-year. The results for the wind energy analysis showed that the annual outputs have significantly less variation than the year-to-year output of individual months for all the locations under study. For the high latitude locations studied, solar energy can still provide useful electricity generation output, but the more pronounced bias of the annual output to the summer months can leave several months with little or no output. The use of additional renewable sources is crucial in beginning to transition some electricity generating capacity within Arctic communities from being solely reliant on fossil fuels.
\end{abstract}

\section{Introduction}

Most remote communities in Canada are not connected to the North American continental electricity distribution network and therefore rely exclusively on diesel generators for electricity production. There is a strong interest developing within many remote communities for successful integration of renewable energy systems to reduce diesel dependency and to increase sustainability and resiliency. Diesel combustion not only emits a high intensity of greenhouse gases, but also emits black carbon which further contributes to global warming through reduction of snow and ice albedo.

Although diesel electricity generation has environmental drawbacks, it is dispatchable and can therefore respond to changes in demand as long as fuel and functional generators are available. This work quantifies the variability of solar and wind resources in several Arctic locations within Canada. Most solar and wind resource assessment tools are limited in the level of detail of their data and analysis. This paper contributes to the gap that exists in detailed solar and wind resource analysis by presenting data on finer time scales over several years. The value of this approach is the ability to assess consistency and intermittency of sustainable energy from solar and wind over their operational life.

\section{Weather data source}

Environment and Climate Change Canada (ECCC) is a governmental department that maintains the Canadian Weather Energy and Engineering Datasets (CWEEDS) [1]. The most recent version of this dataset contains historic hourly weather data for 564 Canadian locations, with most locations having data from 2005 to 2017. The weather datasets are publically available online, and are published in WYEC3 format. In addition to typical observations such as temperature and wind speed at $10 \mathrm{~m}$, solar irradiance data is also provided. Hourly solar is however, primarily modeled data using a technique developed at the State University of New York (SUNY).

To make the weather datasets more accessible to energy modeling tools, all weather data used for this study were converted from WYEC3 to EPW format using the Weather Statistics and Conversion tool from the National Renewable Energy Laboratory (NREL) [2]. This format was initially created for use with the building simulation tool EnergyPlus [2], but is also compatible with several detailed building energy and energy system simulation tools.

\footnotetext{
* Corresponding author: Adam.Wills@nrc-cnrc.gc.ca
} 


\subsection{Climate locations considered}

The six locations selected for this study are geographically dispersed across the north and include some population centres as well as smaller communities:

- Whitehorse, Yukon;

- Inuvik, Northwest Territories;

- Yellowknife, Northwest Territories;

- Cambridge Bay, Nunavut;

- Iqaluit, Nunavut;

- Kuujjuarapik, Québec.

All locations are at a northern latitude greater than $55^{\circ}$, with the most northern location, Cambridge Bay, at a latitude of $69^{\circ}$. The locations also represent different climate types across Canada's North. Annual weather data from 2008 to 2017, inclusive, were processed for each of the locations.

\section{Methodology}

Renewable generation potential for solar and wind sources were analysed and compared using detailed energy models of solar photovoltaic (PV) and wind turbine power conversion systems. Wind kinetic energy and solar radiation energy are different forms of energy, thus making it challenging to compare renewable energy potential at different locations directly from measurements of the natural phenomena. The approach in this work was therefore to compare the renewable energy conversion and generation performance of a solar PV array and wind turbine generator of identical rated capacities at $1.4 \mathrm{~kW}$. Detailed electricity generation modeling of these systems using historic weather data also provides supplementary data beyond rated capacity to energy planners, such as monthly electricity generation estimates, peak power, and finer resolution data.

For this analysis solar and wind conversion and generation was modeled using TRNSYS 18 [3]. TRNSYS is a detailed energy systems simulation tool initially developed to model the performance of solar thermal systems. It has since been expanded to include transient modeling of a variety of energy conversion and transfer systems and components down to sub-hourly timescales. Energy system models are constructed in TRNSYS by linking model subunits, referred to as 'Types', which represent individual components of the system. For this work three Types were used and are described below. For each location and weather year, these models were used to estimate monthly and hourly renewable generation.

\subsection{PV modeling}

Solar conversion and generation was modeled using TRNSYS 18 standard component Type 190. Type 190 is the 5-parameter model developed previously by De Soto et al. [4] which represents PV modules as an equivalent resistor/diode circuit. The characteristics of the circuit components (resistance, etc.) are defined using typically reported manufacturer performance data. The circuit analogy model is then used to estimate PV module performance under operating conditions.

For this analysis, an array of four $350 \mathrm{~W}$ PV modules was modeled using the parameters of a commerciallyavailable poly-crystalline module [5]. The model's 5 parameters were determined using manufacturer data and the TRNSYS PV parameter calculator, summarized in Table 1. Other model inputs may be found in [5].

Table 1. PV model 5-parameter inputs.

\begin{tabular}{|l|c|}
\hline \multicolumn{1}{|c|}{ Parameter } & Value \\
\hline Ideality factor, $a$ & $1.589 \mathrm{eV}$ \\
\hline Light current, $I_{L}$ & $11.25 \mathrm{~A}$ \\
\hline Reverse saturation current, $I_{0}$ & $1.146 \mathrm{E}-10 \mathrm{~A}$ \\
\hline Series resistance, $R_{S}$ & $0.2272 \Omega$ \\
\hline Shunt resistance, $R_{s h}$ & $396.4 \Omega$ \\
\hline
\end{tabular}

For each location considered, the $1.4 \mathrm{~kW}$ PV array was modeled as facing due south with a slope equal to location latitude; according to Duffie and Beckman [6], this slope generally provides optimal solar collection of non-tracking systems.

\subsection{Wind turbine modeling}

Wind conversion and generation was modeled using TRNSYS 18 standard component Type 90. Type 90 is a steady-state empirical model initially developed by Quinlan [7]. The model primarily uses a power output versus wind speed curve to estimate wind turbine performance, where the curve is corrected for the variations in operating condition air density. For this study a performance curve from a commerciallyavailable $1.4 \mathrm{~kW}$ horizontal-axis wind turbine [8] was used. This curve is plotted in Figure 1.

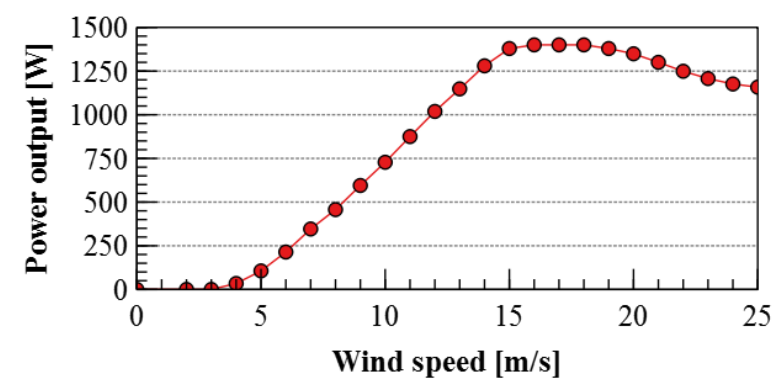

Figure 1. Modeled wind turbine power curve.

The $1.4 \mathrm{~kW}$ rated turbine capacity was selected to correspond to the rated output of the PV array. The cutin speed of the turbine is $2.5 \mathrm{~m} / \mathrm{s}$, and the cut-out is $25 \mathrm{~m} / \mathrm{s}$.

\section{Results}

The results are divided into the following three sections. The first summarizes the annual outputs for all six locations. The second presents the year-to-year variation of the monthly solar and wind electricity production. The third section presents the analysis of 
daily and hourly generation variation focused on Cambridge Bay, Nunavut.

\subsection{Annual outputs}

A summary of the annual outputs for solar and wind are provided in Table 2. The annual solar outputs for these locations are fairly consistent, indicated by the relatively low standard deviation. For wind output, the mean annual output varies significantly across the different locations. Cambridge Bay, Iqaluit, and Kuujjuarapik have very high annual wind output, while the remaining three do not. Although not exhaustive, one of the reasons is that the three highest producing locations are coastal, whereas the three lowest producing locations are inland and not at exposed elevations. Wind measurements at the inland locations could vary significantly with variations in local position. The coefficients of variance (CVs) of the annual wind outputs are far greater relative to the solar CVs. The three highest output locations have a standard deviation of approximately $10 \%$ of the mean and for Yellowknife this figure is over $30 \%$.

Table 2. Annual mean and CV of modeled electricity generation for all locations.

\begin{tabular}{|l|c|c|c|c|}
\hline \multirow{2}{*}{ Location [Latitude] } & \multicolumn{2}{|c|}{ Solar Output } & \multicolumn{2}{c|}{ Wind Output } \\
\cline { 2 - 5 } & $\begin{array}{c}\text { Mean } \\
{[\mathbf{k W h}]}\end{array}$ & $\mathbf{C V}$ & $\begin{array}{c}\text { Mean } \\
{[\mathbf{k W h}]}\end{array}$ & $\mathbf{C V}$ \\
\hline Cambridge Bay $\left[69^{\circ}\right]$ & 1270 & $2.9 \%$ & 1765 & $10.1 \%$ \\
\hline Inuvik $\left[68^{\circ}\right]$ & 1279 & $3.8 \%$ & 265 & $7.2 \%$ \\
\hline Iqaluit $\left[64^{\circ}\right]$ & 1367 & $4.8 \%$ & 1569 & $10.1 \%$ \\
\hline Kuujjuarapik $\left[55^{\circ}\right]$ & 1462 & $4.7 \%$ & 1289 & $10.7 \%$ \\
\hline Whitehorse $\left[61^{\circ}\right]$ & 1347 & $3.3 \%$ & 788 & $12.6 \%$ \\
\hline Yellowknife $\left[62^{\circ}\right]$ & 1402 & $2.9 \%$ & 542 & $32.5 \%$ \\
\hline
\end{tabular}

\subsection{Year-to-year monthly assessments}

Monthly data for both solar PV and wind turbine modeled outputs were tabulated for the six locations and are presented in Figure 3 and Figure 4, respectively. Also provided in the figures are the CVs of the energy outputs for each month of the year, across the ten climate years.

The output from the solar PV system in all locations is shown to be concentrated to the summer months, as expected. The solar output is relatively consistent yearto-year for each month for all locations, as shown by the relatively low $\mathrm{CV}$ values provided in Figure 3. The differences observed are due to atmospheric variations, such as cloud cover or fog. As expected, the highest latitude locations show the most concentration of generation with close to zero production in the core of winter, whereas for the lowest latitude locations it is more spread across summer and winter.

A challenge posed by the concentrated solar production is that peak production is often seasonally mismatched from the peak demand in cold climates. For example, Figure 2 plots the monthly electrical demand of a northern Nunavut community at latitude $68.6^{\circ}$.

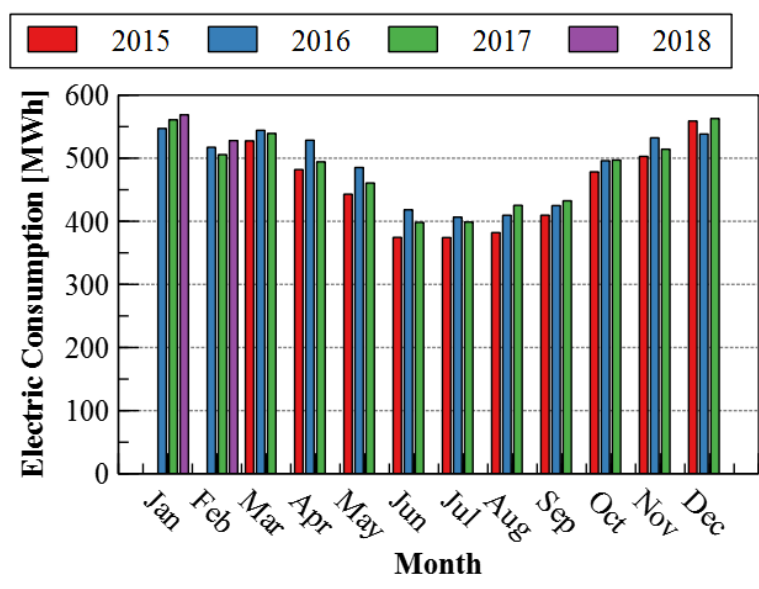

Figure 2. Measured monthly electrical demand for Gjoa Haven, NU, from QEC (as cited in [9])

Figure 2 shows peak demand occurring in December and January, whereas it can be seen in Figure 3 peak solar output occurs in April and May. Another interesting characteristic of Figure 2 is that it suggests the year-to-year variability in community electrical demand is relatively low. This is beneficial as it reduces uncertainty of load estimates for electricity generation planning.

Qualitatively, the modeled wind energy outputs for four of the locations in Figure 4 (Iqaluit, Cambridge Bay, Kuujjuarapik and Whitehorse) show a pattern of producing more during the winter months. Three of the locations; Cambridge Bay, Iqaluit, and Kuujjuarapik, have high output in comparison to the other three locations. The higher output locations have typical monthly outputs of around 100 to $200 \mathrm{kWh}$ per $\mathrm{kW}$, whereas the lower output locations have less than 100 $\mathrm{kWh}$ per $\mathrm{kW}$ output for most of the months evaluated.

The year-to-year outputs for a given month have significantly greater variation for the wind data compared to the solar, with relatively larger $\mathrm{CV}$ values for each month as shown in Figure 4. In fact, the lowest years for a given month are often approximately half of the highest output for that same month in a different year. 


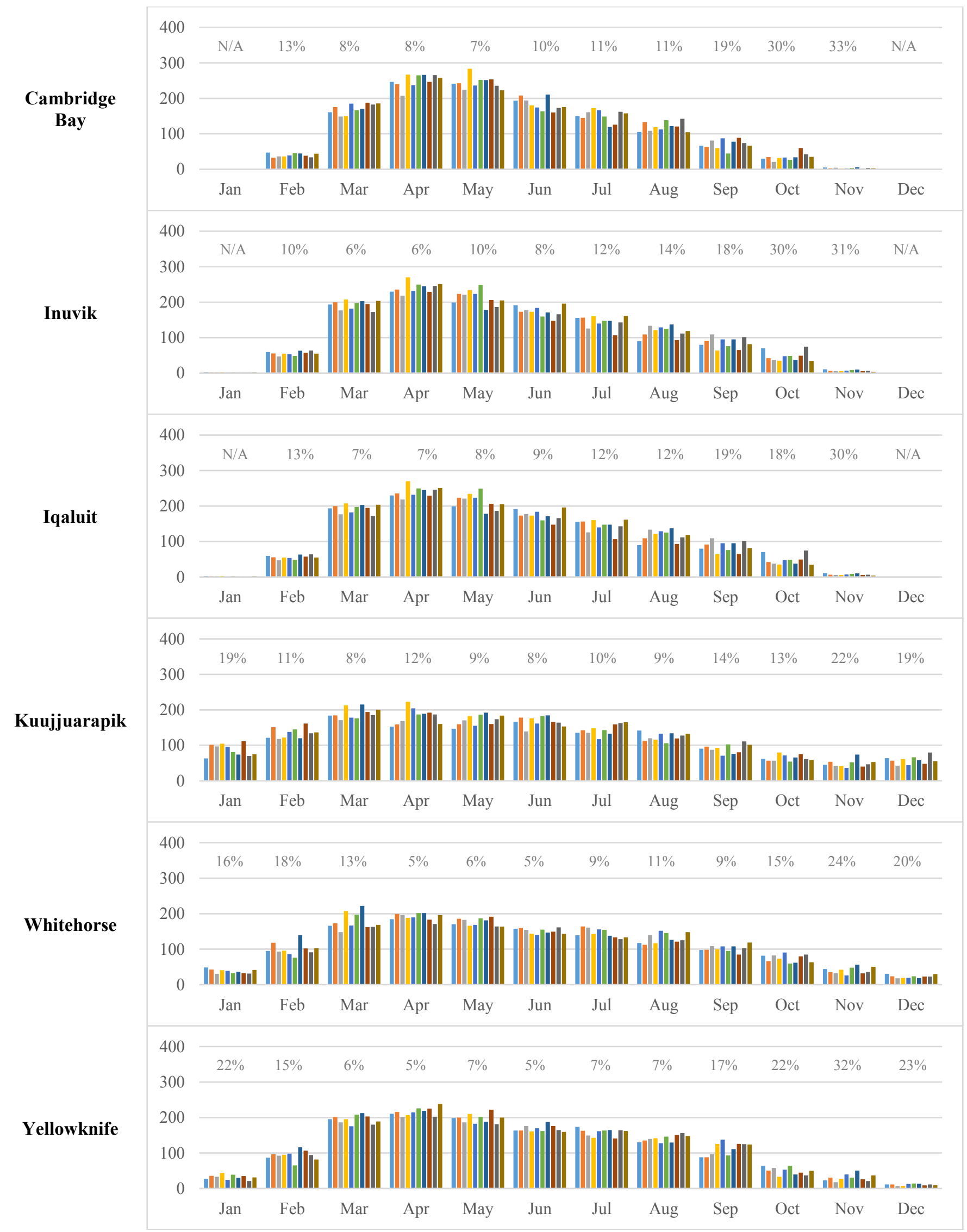

Figure 3. Modeled solar energy output by month per system nominal power output $[\mathrm{kWh} / \mathrm{kW}]$ and CV for each month for 2008-2017 


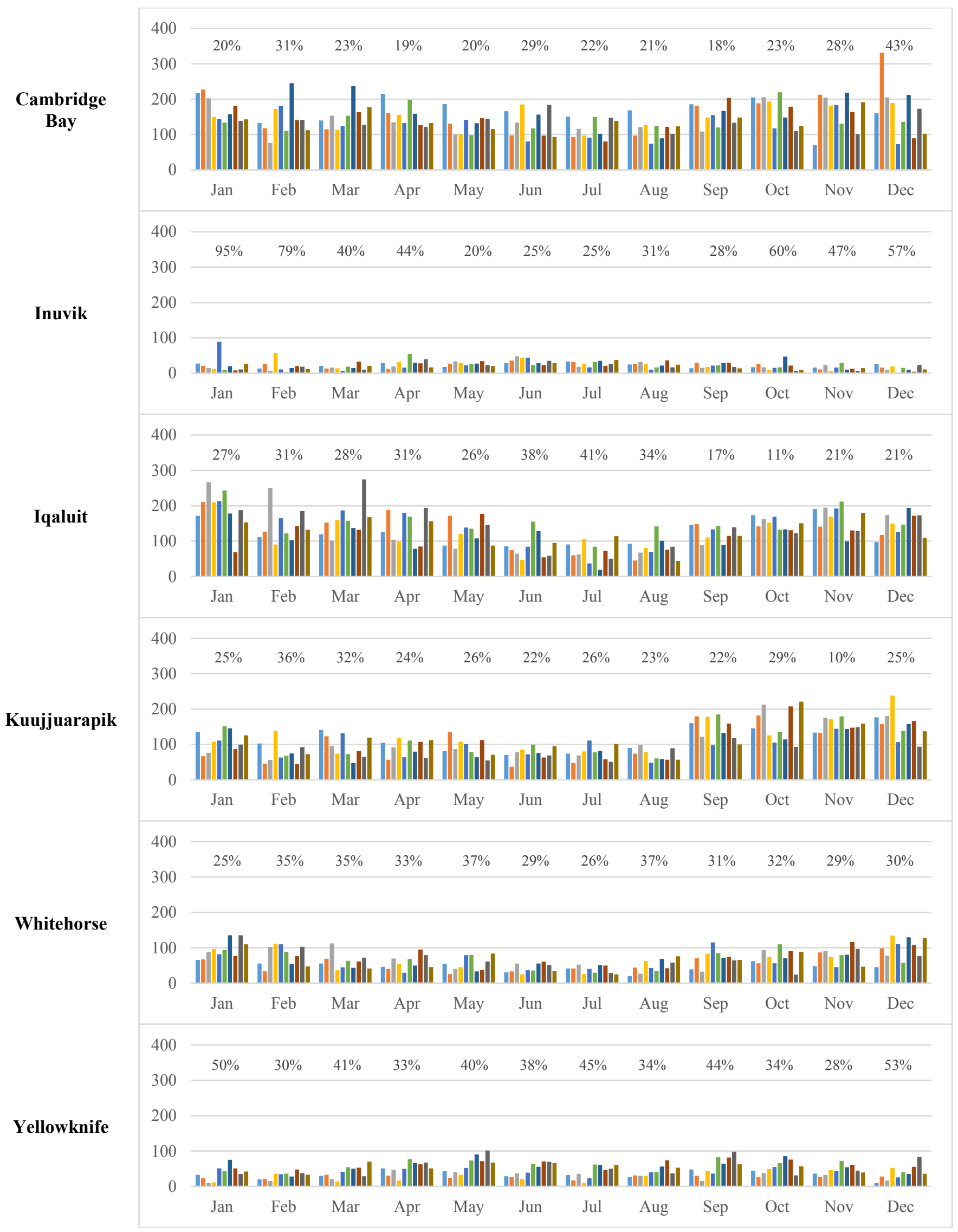

Figure 4. Modeled wind energy output by month per system nominal power output [kWh/kW] and CV for each month for 2008-2017 


\subsection{Daily and hourly assessments}

To examine the impacts of daily and hourly renewable generation variability, the hourly simulation results for Cambridge Bay, Nunavut were considered. Of all locations considered, it is the furthest north with a latitude of $69^{\circ}$. Figures 5 and 6 plot the temporal distribution of hourly solar and wind production modeled using 2017 weather data, respectively. The annual electricity generation for 2017 is 1.75 and 2.23 MWh for solar and wind, respectively.

Similar to what can be seen in Figures 3 and 4, the seasonal variation of electricity generation from solar radiation can be clearly seen in Figure 5. Electricity generation from wind in Figure 6 varies considerably throughout the year with no obvious seasonal pattern visible on this image, although a faint seasonal bias towards increased production in the winter months can be noticed.

It can also be seen in Figure 5 that during periods of high solar production there is less day-to-day generation variation compared to wind generation. To better visualize the day-to-day variation differences, the daily solar and wind production for June is plotted in Figure 7. June was selected since it illustrates the month of highest solar production.

To quantify and compare the daily generation variability the sample means, standard deviations, and CVs of the data in Figure 7 were determined, summarized in Table 3.

Table 3. Mean, standard deviation, and CV of modeled daily electricity generation for Cambridge Bay in June 2017.

\begin{tabular}{|l|c|c|c|}
\hline System & $\begin{array}{c}\text { Mean } \\
{[\mathbf{k W h} / \text { day }]}\end{array}$ & $\begin{array}{c}\text { Std. Dev. } \\
{[\mathbf{k W h} / \text { day }]}\end{array}$ & CV [\%] \\
\hline Solar & 8.20 & 2.45 & $30 \%$ \\
\hline Wind & 4.33 & 3.13 & $72 \%$ \\
\hline
\end{tabular}

The relatively high CV for wind compared to solar demonstrates the high variability of wind production compared to solar.

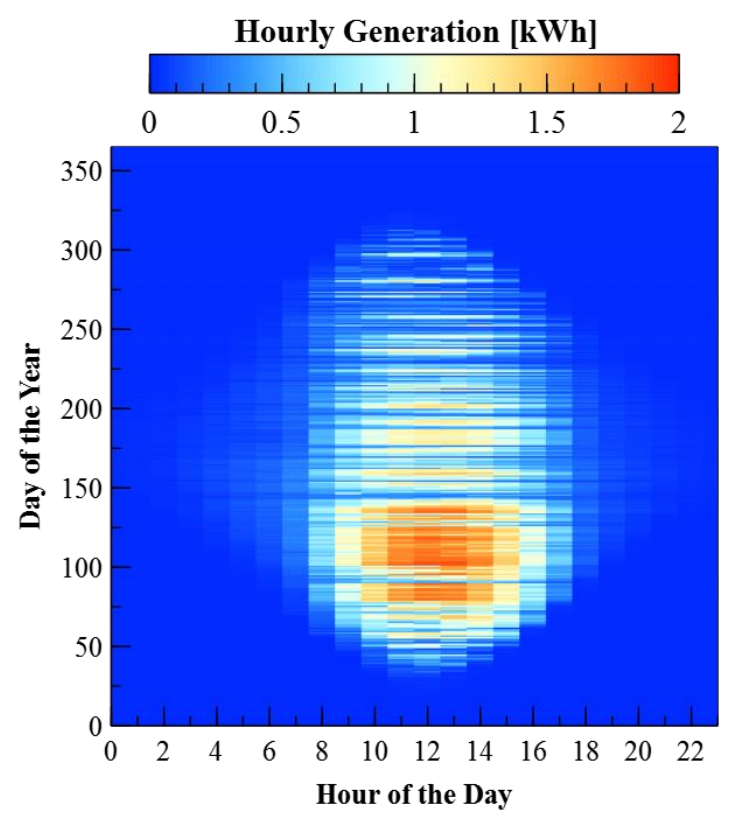

Figure 5. Modeled solar generation for 2017 in Cambridge Bay.

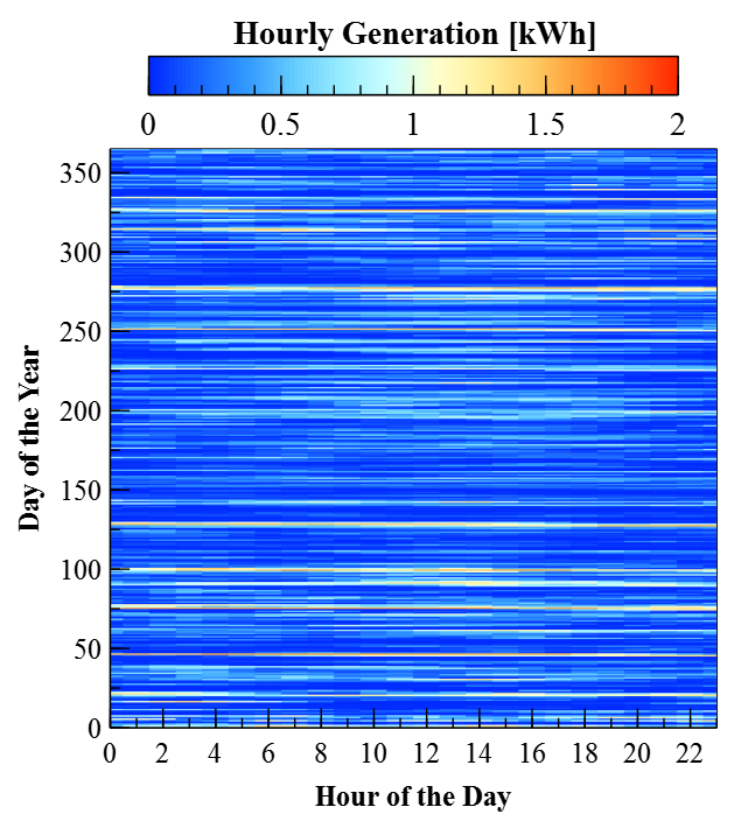

Figure 6. Modeled wind generation for 2017 in Cambridge Bay.

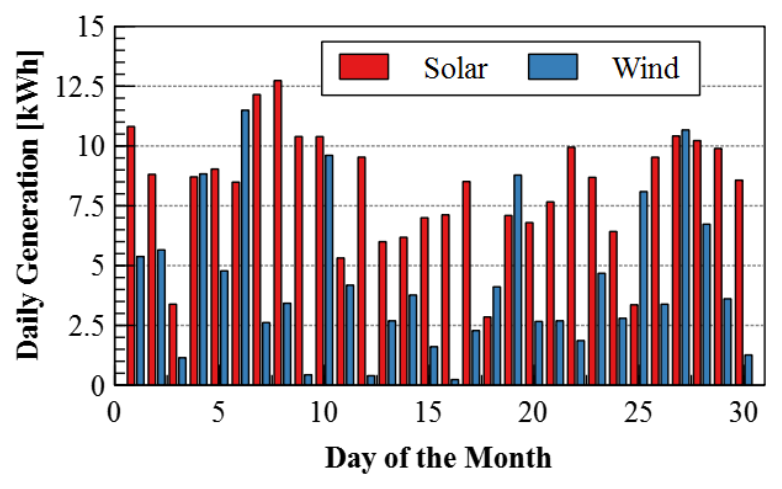

Figure 7. Modeled daily solar and wind generation for June 2017 in Cambridge Bay. 


\section{Discussion}

One of the big challenges of solar and wind energy is that they are both intermittent and non-dispatchable. This analysis looked at the variability of these renewable resources over ten years of weather data for 6 locations in the Arctic. The analysis shows that solar PV systems can be expected to provide a consistent annual energy output from year-to-year for the locations studied. A wind energy system in these locations would have more variation in annual output based on this modeling.

A demand profile for a community in the Canadian Arctic was presented as an example. However, the application of this work is not focused specifically on community-scale renewable energy projects. Individual building demands could be expected to mirror the seasonal trend seen for an overall community of higher electricity demands in the winter months and lower during the summer months. Possible reasons for these trends is more electricity use by HVAC equipment, engine block heating, appliances, lighting and plug loads as occupants spend more time indoors during the winter months. Note that space and water heating loads in the Arctic are almost universally met using diesel fuel, not electricity.

The electricity generation from solar radiation varies from month-to-month as a result of the geometry between the sun and earth, but its monthly output is much more consistent than wind energy from year-toyear. This could form a significant base output for Arctic communities during the six sunniest months of the year.

Although wind energy output is more variable on annual, monthly, daily, and hourly timescales, its distribution throughout the year is far more spread out compared to the seasonally concentrated output of solar. As a result, solar output can be predicted better on all timescales, but wind output is better able to meet demands throughout the course of a year.

\section{Conclusions and future work}

The combination of solar and wind energy is expectedly variable and often out of sync with building electricity demands in the Arctic. These renewable energy sources are not expected to meet the full energy demands of Arctic communities, but the near-term goal is to increase reliable renewable energy deployment in these communities to reduce diesel use, build local capacity for the required skills, and gain confidence in the products and installation techniques.

Based on the analysis of the six Arctic locations it was determined that wind generation systems nominally achieve more annual energy production per system power rating compared to solar for two of the six locations studied. Even for the locations with lower annual normalized output, it can still make sense to install wind power due to its more favourable distribution throughout the year.

The data also illustrated that across all Arctic locations wind generation is more spread throughout the year, whereas peak solar production and peak electric demand are seasonally mismatched, as expected. However, the multi-year energy analysis highlighted that year-to-year solar production is more consistent compared to wind, both for monthly and total annual production. Therefore, it is important to consider the combination of renewable sources to balance their strengths and weaknesses.

To bridge the gap between renewable generation and demand, energy storage is often used. For all energy storage systems there are associated losses associated with charge/discharge and losses to ambient. Future work will explore the integration of energy storage with wind and solar, and analyse the optimal balances of wind, solar, and energy storage to achieve high renewable energy penetration without impractical storage capacity requirements. Future analyses will also explore the robustness of these optimal solutions across several weather years.

\section{References}

[1] ECCC, "Engineering Climate Datasets," Government of Canada, 24 Mar 2018. [Online]. Available: http://climate.weather.gc.ca/prods_servs/engineering e.html. [Accessed 31 May 2018].

[2] NREL, "EnergyPlus," U.S. Department of Energy, 2020. [Online]. Available: https://energyplus.net/. [Accessed 13 January 2021].

[3] TESS, "TRNSYS: Transient System Simulation Tool," 2019. [Online]. Available: http://www.trnsys.com/. [Accessed 26 July 2019].

[4] W. De Soto, S. A. Klein and W. A. Beckman, "Improvement and validation of a model for photovoltaic array performance," Solar energy, pp. 78-88, 2006.

[5] Canadian Solar, "HiKu High Power Poly Perc Module 325 W 350 W," Canadian Solar Inc., Guelph, 2020.

[6] J. A. Duffie and W. A. Beckman, Solar Engineering of Thermal Processes, Hoboken: John Wiley \& Sons, 2006.

[7] P. J. A. Quinlan, Time series modelling of hybrid wind photovoltaic diesel power systems, Madison: University of Wisconsin-Madison, 1996.

[8] Fortis, "Fortis Wind Energy Passaat Wind Turbine Instruction Manual," Fortis Wind BV, Haren, 2013.

[9] WWF, "Community Energy Report: Gjoa Haven," World Wide Fund For Nature, Gland, 2018.

[10] ECCC, "Winter 2015 to 2016: Climate Trends and Variations Bulletin," Environment and Climate Change Canada, 2017. [Online]. Available: https://www.ec.gc.ca/sccs/default.asp?lang $=$ En $\& n=55965$ A8C $1 \&$ wbdisable=true. [Accessed 13 January 2021]. 